Article

\title{
Improving Remote Sensing of Aerosol Optical Depth over Land by Polarimetric Measurements at 1640 nm: Airborne Test in North China
}

\author{
Lili Qie ${ }^{1}$, Zhengqiang Li ${ }^{1, *}$, Xiaobing Sun ${ }^{2,3}$, Bin Sun ${ }^{2,3}$, Donghui Li ${ }^{1}$, Zhao Liu ${ }^{1,4, \dagger}$, \\ Wei Huang ${ }^{1,4, \dagger}$, Han Wang ${ }^{2,3}$, Xingfeng Chen ${ }^{1}$, Weizhen Hou ${ }^{1}$ and Yanli Qiao ${ }^{2,3}$
}

1 State Environmental Protection Key Laboratory of Satellite Remote Sensing, Institute of Remote Sensing and Digital Earth, Chinese Academy of Sciences, Beijing 100101, China; E-Mails: qiell@radi.ac.cn (L.Q.); lidh@radi.ac.cn (D.L.); liuzh07@163.com (Z.L.); huangwei@radi.ac.cn (W.H.); chenxf@radi.ac.cn (X.C.); houwz@radi.ac.cn (W.H.)

2 Anhui Institute of Optics and Fine Mechanics, Chinese Academy of Sciences, Hefei 230031, China; E-Mails: xbsun@aiofm.ac.cn (X.S.); sunbin@aiofm.ac.cn(B.S.); ms.h.wang@163.com (H.W.); ylqiao@aiofm.ac.cn (Y.Q.)

3 Key Laboratory of Optical Calibration and Characterization, Chinese Academy of Sciences, Hefei 230031, China

4 University of Chinese Academy of Sciences, Beijing 100049, China

$\dagger$ These authors contributed equally to this work.

* Author to whom correspondence should be addressed; E-Mail: lizq@radi.ac.cn; Tel.: +86-10-6485-7437; Fax: +86-10-6480-6225.

Academic Editors: Richard Müller and Prasad S. Thenkabail

Received: 18 February 2015 / Accepted: 13 May 2015 / Published: 19 May 2015

\begin{abstract}
An improved aerosol retrieval algorithm based on the Advanced Multi-angular Polarized Radiometer (AMPR) is presented to illustrate the utility of additional 1640-nm observations for measuring aerosol optical depth (AOD) over land using look-up table approaches. Spectral neutrality of the polarized surface reflectance over visible to short-wavelength infrared bands is verified, and the $1640-\mathrm{nm}$ measurements corrected for atmospheric effects are used to estimate the polarized surface reflectance at shorter wavelengths. The AMPR measurements over the Beijing-Tianjin-Hebei region in north China reveal that the polarized surface reflectance of 670,865 and $1640 \mathrm{~nm}$ are highly correlated with correlation slopes close to one ( 0.985 and 1.03$)$ when the scattering angle is
\end{abstract}


less than $145^{\circ}$. The $1640-\mathrm{nm}$ measurements are then employed to estimate polarized surface reflectance at shorter wavelengths for each single viewing direction, which are then used to improve the retrieval of AOD over land. The comparison between AMPR retrievals and ground-based Sun-sky radiometer measurements during three experimental flights illustrates that this approach retrieves AOD at $865 \mathrm{~nm}$ with uncertainties ranging from 0.01 to 0.06 , while AOD varies from 0.05 to 0.17 .

Keywords: aerosol optical depth (AOD); polarized surface reflectance; $1640 \mathrm{~nm}$; airborne Advanced Multi-angle Polarized Radiometer (AMPR)

\section{Introduction}

The interactions of aerosols with atmospheric composition and radiation are complex. Aerosols scatter and/or absorb solar and terrestrial radiation and act as cloud condensation nuclei, modifying the properties of clouds and their lifetimes, and thus influence the terrestrial climate system. Aerosols are generated both naturally and anthropogenically and exhibit large spatial and temporal variability in their concentrations and physico-chemical properties. The direct and indirect effects of aerosol continue to contribute the largest uncertainty of the total radiative forcing estimate [1].

Satellite remote sensing offers global and quasi-continuous monitoring of aerosol properties. The development of space-borne sensors has provided a considerable amount of observations on global aerosol in the past few decades. Satellites derive information on aerosol load, microphysical parameters and chemical compositions by detecting the sunlight reflected from the Earth-atmosphere system at specific bands. One of the challenges in aerosol remote sensing from space is separating aerosol contribution from that of the underlying surface. This separation is critical to obtain accurate aerosol parameters. The retrieval of aerosols over the ocean, on which the surface is dark enough, can be reasonably estimated in terms of the variability of chlorophyll concentration $[2,3]$. However, aerosol retrieval over land surfaces is much more difficult, because the aerosol contribution is generally smaller than that of the surface, and the surface albedo strongly depends on the land surface type and vegetation coverage. Several methods have been developed for aerosol retrieval over land. The dark surface target approach, which was first developed for the Moderate-resolution Imaging Spectrometer (MODIS), retrieves aerosol optical depth (AOD), where the surface contribution is minimized [4]. This approach was further extended to brighter surfaces using correlations between the surface reflection in the visible and short-wave infrared (SWIR) bands for many surface types [5]. The Along-Track Scanning Radiometer (i.e., ATSR [6] and AATSR (Advanced Along-Track Scanning Radiometer) [7]) and the Multiangle Imaging Spectroradiometer (MISR) [8] take advantage of differing angular reflectance signatures of the surface and atmosphere to accomplish retrieval of aerosol properties over land. The Total Ozone Mapping Spectrometer (TOMS) and the Ozone Monitoring Instrument (OMI), taking the advantages of the low surface albedo at near-ultraviolet (UV) bands and the larger sensitivity to aerosol absorption in the near-UV, were developed to study absorbing aerosols, such as dust and biomass burning aerosols [9-11]. The use of a pre-estimated surface reflectance database is another approach to estimate surface contribution [12]. Each approach mentioned is successful either for 
specific aerosols or certain surface types, both of which influence the retrieval accuracy. Highly accurate satellite remote sensing of aerosol over land remains a challenge.

Polarized measurements provide an alternative and robust approach to the study of aerosols over land. Using polarized radiances, compared with total radiances, has several advantages. The polarized surface contribution is usually smaller than that of the atmosphere and is observed with minimal spectral dependence and generally weak spatial contrast [13-15]. Moreover, polarized measurements exhibit high sensitivity to aerosol properties [16]. The series of Polarization and Directionality of Earth Reflectance instruments (i.e., POLDER I, II and POLDER on board PARASOL (Polarization \& Anisotropy of Reflectances for Atmospheric Sciences coupled with Observations from a Lidar) [17]) collected angular measurements of both total and polarization radiances from visible to near-infrared bands to retrieve AOD, particle size parameters [17] and even the information on particle shapes and aerosol layer height [18]. Airborne prototypes, such as the Micropolarimeter (MICROPOL) [19], the Research Scanning Polarimeter (RSP) [16] and the Airborne Multiangle Spectropolarimetric Imager (AirMSPI) [20], are essential to the study of the polarization properties of the surface-atmosphere system and to test or improve the aerosol retrieval algorithms. MICROPOL is a single viewing angle prototype polarimeter developed by the Laboratoire d'Optique Atmosphérique, Université de Lille, France. This polarimeter can provide accurate polarized measurements at five spectral bands from $490 \mathrm{~nm}$ to 2200 $\mathrm{nm}$, from which AOD and size parameters are derived [14,19]. RSP is an airborne simulator for the advanced Aerosol Polarimetry Sensor (APS) that was expected to launch on board the NASA Glory satellite. RSP provides polarized observations over a broad spectral range from $410 \mathrm{~nm}$ to $2250 \mathrm{~nm}$ and 152 viewing angles, scanning continuously over a range of $\pm 60^{\circ}$ around nadir [21]. RSP (or APS) aims to accurately retrieve a set of aerosol and cloud parameters using optimal retrieval algorithms [22]. AirMSPI is an airborne prototype of a future satellite-borne MSPI instrument for obtaining multi-angle polarization imagery. It is an eight-band (with a spectral range from $355 \mathrm{~nm}$ to $935 \mathrm{~nm}$ ) pushbroom camera that measures polarization at the 470-, 660- and $865-\mathrm{nm}$ bands, while acquiring multiangular observation over a $\pm 67^{\circ}$ along-track range, which enables retrieval of aerosol and cloud microphysical properties and cloud 3D spatial distributions [20]. MICROPOL and RSP evaluated the surface contribution from 2250-nm band polarized measurements, because its atmospheric contribution is negligible; thus, the limitation of using a semi-empirical model for surface correction in aerosol retrieval over land can be overcome [23]. However, spaceborne polarized measurement at a wavelength of 2250 $\mathrm{nm}$ remains a challenge in terms of instrumental aspects, because the detectors used in infrared channels usually need to be passively cooled and controlled to a stable temperature; otherwise, the measurement accuracy is compromised. The present study focuses on using an alternative shorter wavelength (1640 $\mathrm{nm}$ ) to estimate polarized surface reflectance for aerosol retrieval, which is significantly easier to achieve without cooling detectors.

To study aerosol and surface-polarized properties and to monitor aerosol and clouds, Anhui Institute of Optics and Fine Mechanics, Chinese Academy of Sciences (AIOFM, CAS), developed an RSP-like instrument named the Advanced Multi-angular Polarized Radiometer (AMPR) [24]. The detection approaches and capabilities of AMPR are similar to that of RSP, except that its longest operating wavelength is $1640 \mathrm{~nm}$, where the atmospheric contribution is small, but not negligible. In recent years, AMPR had participated in several aircraft and ground-based remote-sensing experiments in the Beijing-Tianjin-Hebei region in the north of China. This study presents and evaluates the capacity of 
1640-nm polarized measurements to estimate polarized surface reflectance in retrieving aerosol properties over land. A multiband polarized algorithm was employed to retrieve AOD over land using the polarized radiance measurements from $670 \mathrm{~nm}$ to $1640 \mathrm{~nm}$. First, we investigated and validated the spectral neutrality of polarized surface reflectance within the range from $670 \mathrm{~nm}$ to $1640 \mathrm{~nm}$. The algorithm was then presented to retrieve AOD from AMPR measurements over vegetated surfaces, and the results were compared to observations from ground-based CE318 (CIMEL company) Sun-sky radiometers to test the capacity of the AMPR in deriving aerosol properties over land.

\section{Field Experiment}

\subsection{AMPR Instrument}

AMPR is an airborne polarimeter with 6 spectral bands centered at 490 (30), 555 (30), 670 (40), 865 (40), 960 (40) and 1640 (40) $\mathrm{nm}$ (the full width at half maximum of each band is also given inside parentheses). All of these bands are designed to detect aerosol and cloud, except for the water vapor band centered at $960 \mathrm{~nm}$, where a major water vapor absorption band is located. Two Wollaston prisms are used to simultaneously detect the polarization states at 4 azimuths of $0^{\circ}, 45^{\circ}, 90^{\circ}$ and $135^{\circ}$. Total radiances and polarized radiances are measured at all bands. Multi-angular measurements are acquired by scanning the fields of view through $\pm 55^{\circ}$ around nadir, with a sampling interval of $1^{\circ}$, thereby yielding 111 scattering angles per scanning course. AMPR can be operated to scan in along-track mode or cross-track mode depending on the mounting type on the aircraft. AMPR in along-track mode provides multi-angular detection to pixels along the ground track, whereas that in cross-track mode provides single viewing measurements over the image covering the scanning swath. During a scan course of $0.863 \mathrm{~s}$, the scene signals, calibration records and dark references are collected. The instantaneous field of view of AMPR is $1^{\circ}$, and the pixel size is approximately $60 \mathrm{~m}$, which corresponds to a standard flight altitude of $3.6 \mathrm{~km}$.

The first three Stokes parameters $[I, Q, U][25]$ can be derived from AMPR measurements, where $I$ represents total radiance and $Q$ and $U$ describe the intensity and direction of linear polarization. In aerosol retrieval, the observed radiance is usually converted to reflectance. The total and polarized bidirectional reflectance factors are calculated as follows:

$$
\begin{gathered}
R=\frac{\pi I}{E_{0} \mu_{0}} \\
R p=\frac{\pi \sqrt{Q^{2}+U^{2}}}{E_{0} \mu_{0}}
\end{gathered}
$$

where $E_{0}$ is the extraterrestrial solar spectral irradiance and $\mu_{0}$ is the cosine of the solar zenith angle.

\subsection{Field Experiments}

On 10 August 2012 and 18 September 2014, the AMPR instrument was integrated onto an aircraft, and three flights were performed in the Beijing-Tianjin-Hebei region, the north of China. The main purpose of the experiments was to acquire AMPR aircraft observations and characterize aerosol and surface optical properties. All three flights were performed in sunny and clear weather conditions. The 
flight track of the first and second flights on 10 August 2012 is indicated by the green line in Figure 1; the track starts from Binhai airport in Tianjin city, covering the east of Tianjin, south of Tangshan and a corner of Bohai Bay. The track of the third flight on 18 September 2014 is illustrated by the red line, which starts from Caofeidian on the edge of Bohai Sea, passes over Fengnan in Hebei province and ends at Xianghe in Beijing. Additional information on the three flights, including date and time, area, altitude and scanning modes, is listed in Table 1. The scanning modes of the first and third flights are along-track, whereas the second one is cross-track. Pre- and post-flight calibrations were implemented in the laboratory to guarantee measurement accuracy. The calibration results show that the radiometric measurement accuracy of AMPR is better than 5\%, and the polarimetric accuracy is better than 0.005 in the degree of linear polarization [26,27].

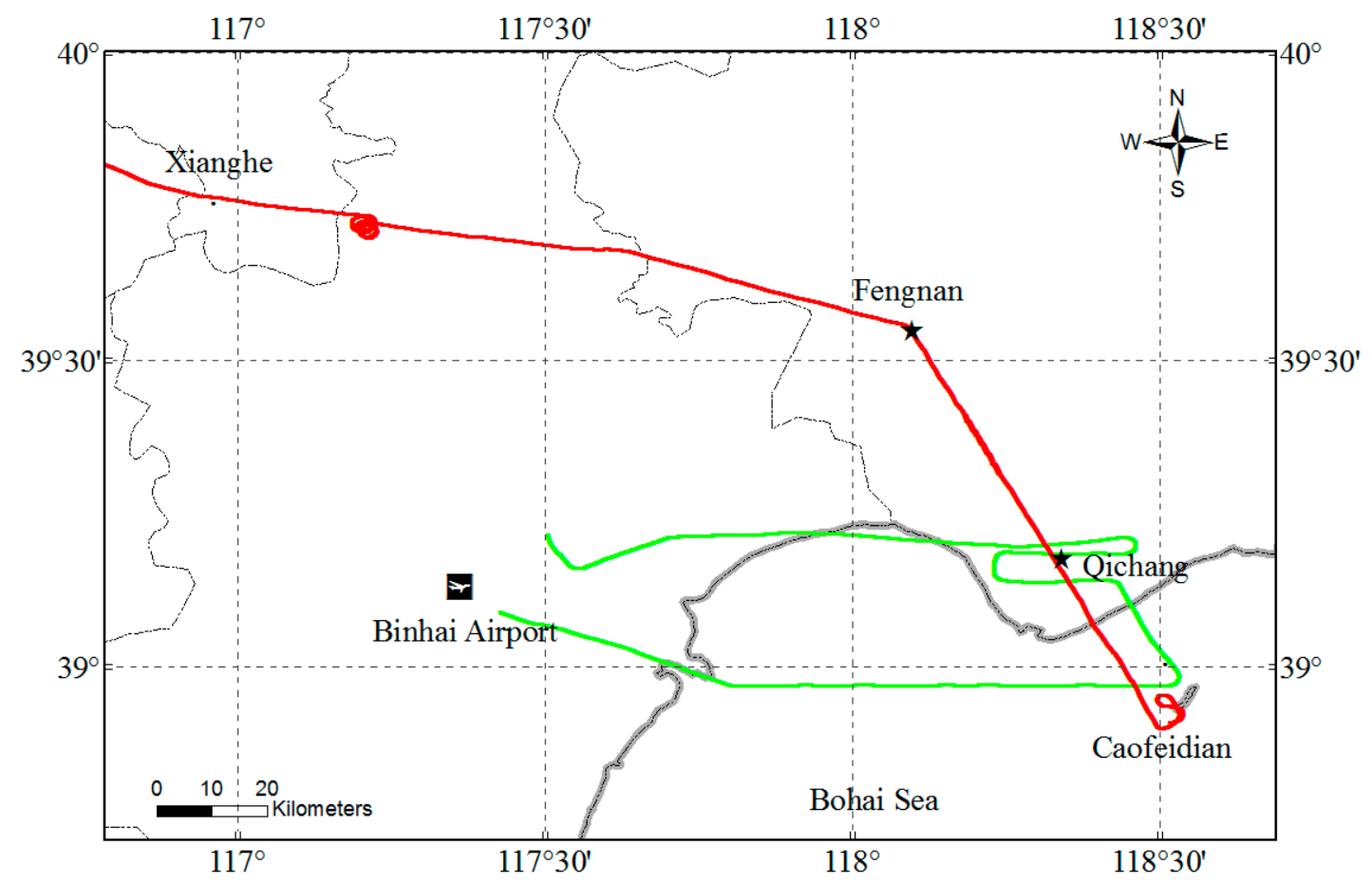

Figure 1. Flight tracks of the first and second flights on 10 August 2012 (green line) and that of the third flight on 18 September 2014 (red line). Star symbols indicate ground-based CE318 Sun-sky radiometer sites for validation. The dashed square is the research area for Flights 1 and 2.

Table 1. Flight information of AMPR test experiments.

\begin{tabular}{cccccc}
\hline Flight & Date & Time $(\mathbf{G}+\mathbf{8})$ & Flight Area & Flight Altitude $(\mathbf{k m})$ & Scan Mode \\
\hline 1 & 2012.8 .10 & $09: 50$ to $10: 53$ & $117.3^{\circ}$ to $118.6^{\circ} \mathrm{E}, 38.9^{\circ}$ to $39.21^{\circ} \mathrm{N}$ & 3.1 & Along Track \\
2 & 2012.8 .10 & $13: 42$ to $14: 47$ & $117.3^{\circ}$ to $118.6^{\circ} \mathrm{E}, 38.9^{\circ}$ to $39.21^{\circ} \mathrm{N}$ & 3.2 & Cross Track \\
3 & 2014.9 .18 & $11: 32$ to $12: 48$ & $116.7^{\circ}$ to $118.5^{\circ} \mathrm{E}, 38.8^{\circ}$ to $39.8^{\circ} \mathrm{N}$ & 3.6 & Along Track \\
\hline
\end{tabular}

Several temporal ground-based stations of the Sun-sky Radiometer Observation Network (SONET) [28] were set up in the experiment areas, equipped with automatic Sun-sky radiometer CIMEL CE318, which is also the standard instrument of the Aerosol Robotic Network (AERONET) [29]. The locations of these stations are presented in Figure 1. On 10 August 2012, the ground-based validation 
station is Qichang site $\left(39.1773^{\circ} \mathrm{N}, 118.3404^{\circ} \mathrm{E}\right)$, located northeast of the flight area, approximately $1 \mathrm{~km}$ away from the flight track. On 18 September 2014, the corresponding station is Fengnan site $\left(39.5464^{\circ} \mathrm{N}, 118.0964^{\circ} \mathrm{E}\right)$, located on the flight track. The CE318 worked continuously during the experiments; the operational process of SONET provided reference spectral AOD from $340 \mathrm{~nm}$ to 1640 $\mathrm{nm}$ (with uncertainties of 0.01 to 0.02 ), the aerosol complex refractive indices and the particle size distribution [28]. These aerosol parameters were used to constrain and validate the AMPR retrievals.

Several vegetated surface areas from the three AMPR observations were selected as the research areas, where the surface cover is relatively homogeneous. The research areas for the first and second flights are marked in Figure 1 with a dashed square, and that for the third flight is the section from Caofeidian to Fengnan. Details on the selected study areas are provided in Table 2. The Sun-sky radiometer observations on the second flight suggested a very clear sky condition with very low AOD at $870 \mathrm{~nm}$ (about 0.06), whereas the sky is also clear, but with higher AOD around 0.15 on the first and third flights. The available scanning zenith angle range was from $-38^{\circ}$ to $29^{\circ}$ for the first and second flights and from $-38^{\circ}$ to $25^{\circ}$ for the third flight, because of a partly blocked instrument field of view by the airplane body, yielding 68 and 64 viewing angles, respectively. The range of the scattering angles for the three selected study flights depended on the solar position, flight direction and scanning mode, which are also presented in Table 2.

Table 2. Characteristics of the selected research areas.

\begin{tabular}{cccccc}
\hline Flight & \multirow{2}{*}{ Time $(\mathbf{G}+\mathbf{8})$} & Solar and Viewing Geometry & Scan Numbers & $\begin{array}{c}\text { CE318's AOD } \\
(\mathbf{8 7 0} \mathbf{n m})\end{array}$ \\
\hline 1 & $10: 25: 19$ to $10: 40: 26$ & $\theta_{s}: \sim 32^{\circ} ; \theta_{v}:-38^{\circ}-29^{\circ} \varphi_{r}: 40^{\circ}, 140^{\circ} ; \Theta: 110^{\circ}-160^{\circ}$ & 815 & $\sim 0.15$ \\
2 & $14: 15: 30$ to $14: 28: 54$ & $\theta_{s}: \sim 37^{\circ} ; \theta_{v}:-38^{\circ}-29^{\circ} \varphi_{r}: 60^{\circ}, 120^{\circ} ; \Theta: 110^{\circ}-155^{\circ}$ & 715 & $\sim 0.06$ \\
3 & $11: 38: 13$ to $12: 01: 37$ & $\theta_{s}: \sim 37^{\circ} ; \theta_{v}:-38^{\circ}-25^{\circ} \varphi_{r}: 20^{\circ}, 160^{\circ} ; \Theta: 115^{\circ}-170^{\circ}$ & 1145 & $\sim 0.14$ \\
\hline
\end{tabular}

Notes: $\theta_{s}, \theta_{v}, \varphi_{r}$ and $\Theta$ are the solar zenith angle, viewing zenith angle (i.e., scanning zenith angle), relative azimuth angle and scattering angle, respectively.

\section{Aerosol Retrieval Method}

In this study, we use the polarization measurements at the 670-, 865- and 1640-nm bands to retrieve AOD over land, based on the look-up table (LUT) approach. The 1640-nm measurements are specifically focused on providing the polarized surface information at shorter wavelengths, whereas the 670- and 865-nm measurements are simultaneously used to retrieve AOD based on the work of Deuzé et al. [23]. The 490-nm and 555-nm measurements are discarded because the molecular optical depths are much higher at shorter wavelengths, and the aerosol contributions are relatively lower in weight [23]. AOD and aerosol model associated with the best fit between the measurements of polarized atmosphere-only reflectance and the pre-calculated one in the LUT are accepted as retrieval results.

\subsection{Modelling of Polarized Reflectance}

The upwelling polarized radiance at the top of atmosphere (TOA) can be modelled as the sum of the polarized radiance generated by atmospheric and single reflection of the surface [14,23]. The upward polarized reflectance measured at the sensor level $z$ can be expressed as:

$$
R p_{\lambda}{ }^{\text {meas }}\left(z, \theta_{s}, \theta_{v}, \phi_{r}\right)=R p_{\lambda}{ }^{a t m}\left(z, \theta_{s}, \theta_{v}, \phi_{r}\right)+R p_{\lambda}{ }^{\text {surf }}\left(\theta_{s}, \theta_{v}, \phi_{r}\right) \cdot T_{\lambda}^{\downarrow}\left(\theta_{s}\right) \cdot T_{\lambda}^{\uparrow}\left(z, \theta_{v}\right)
$$


where $\lambda$ is the wavelength; and $\theta_{s}, \theta_{v}$ and $\varphi_{r}$ are the solar zenith angle, viewing zenith angle and relative azimuth angle, respectively. The first term $R p_{\lambda}{ }^{a t m}$ on the right side is the polarized atmospheric path reflectance (i.e., the polarized reflectance for an atmosphere above a black surface), and the $R p^{\text {surf }}$ in the second term is the bidirectional polarized reflectance of the surface. $T_{\lambda}^{\downarrow}$ and $T_{\lambda}^{\uparrow}$ are the downward and upward transmission terms, respectively, and can be computed using the following equations [30]:

$$
\begin{gathered}
T_{\lambda}^{\downarrow}\left(\theta_{s}\right)=\exp \left[-\frac{\psi \tau^{m}(0)+\zeta \tau^{a}(0)}{\mu_{s}}\right] \\
T_{\lambda}^{\uparrow}\left(z, \theta_{v}\right)=\exp \left[-\frac{\psi \tau^{m}(z)+\zeta \tau^{a}(z)}{\mu_{s}}\right]
\end{gathered}
$$

where $\tau(0)$ and $\tau(z)$ are optical depth from the ground to TOA and altitude $z$, respectively. The superscripts ${ }^{m}$ and ${ }^{a}$ represent molecules and aerosols, respectively. The coefficients $\psi$ and $\zeta$ account for diffuse transmission contributions of light from aerosols and molecules, which are not accounted for in Equation (3). $\psi$ is equal to 0.9. $\zeta$ depends on the aerosol model. Lafrance [31] developed the empirical expression:

$$
\zeta=0.3658+0.1023 \alpha+0.0080 \alpha^{2}
$$

where $\alpha$ is the Ángström coefficient defined by the AODs at $670 \mathrm{~nm}$ and $865 \mathrm{~nm}$. It is worth noting that the Ángström coefficient here may cause uncertainty in $\zeta$ and then in $T_{\lambda}^{\downarrow}$ and $T_{\lambda}^{\uparrow}$, because of the relatively small AOD difference between these two nearby wavelengths. Based on the estimation of Lafrance [31] and Waquet et al. [14], Equation (3) can model the polarized reflectance with an absolute error less than 0.0002 for AOD smaller than 0.1 at $670 \mathrm{~nm}$ when the viewing and illumination angles are smaller than $60^{\circ}$. The accuracy of Equation (3) decreases with the increase of optical depth.

Laboratory and airborne measurements indicate that the polarized reflectance from several kinds of surfaces, such as forest, vegetation and bare soils, are spectrally neutral from the visible to SWIR bands [13-15,32-34], which is consistent with the hypothesis that the surface reflected polarization is generated mainly by the specular reflection at the surface interface, and it can be approximately modelled based on the Fresnel reflection [30]. Consequently, the polarization measurements at near-infrared or SWIR bands (i.e., $1640 \mathrm{~nm}$ ) corrected for atmospheric effect can derive the polarized surface reflectance at shorter bands.

\subsection{Look-Up Table}

A pre-computed LUT of atmospheric polarized reflectance is used to derive AOD considering a set of assumed aerosol models. Omar et al. [35] classified global atmospheric aerosols into six clusters using a clustering algorithm based on the complete archive of the AERONET dataset for nearly 10 years. Six significant aerosol models were then established from the clusters and denote desert dust aerosol, biomass burning aerosol, background/rural aerosol, polluted continental aerosol, polluted marine aerosol and dirty pollution aerosol. Desert dust is coarse mode dominant and assumed to be mostly mineral soil. Biomass burning aerosol is predominantly fine mode aerosol, consisting primarily of soot and organic carbon with an average single scattering albedo (SSA) of 0.8. Polluted continental aerosol and dirty pollution aerosol have a similar size distribution that is fine mode dominant, whereas the dirty 
pollution aerosol has a larger imaginary index of refraction and smaller SSA (0.72). Polluted marine aerosol is marine aerosol (coarse mode) mixed with biomass burning smoke or industrial pollution (fine mode). Background/rural aerosol usually occurs in clean continental and rural background areas and is characterized by low optical depth [35]. The detailed microphysical and optical properties of these models, including the complex refractivity index, size distribution, Ángström coefficient and SSA, are listed in Table 2 of [35]. These models were employed in the present study to construct LUT, and Mie theory is used to calculate the optical parameters (i.e., scattering matrix) of the models.

In this paper, the atmosphere is considered to be plane-parallel, and the optical properties vary only in the vertical direction. The extinction coefficients of aerosols and molecules exponentially decrease with height. The molecular scale height is set to the standard value of $8 \mathrm{~km}$, whereas the aerosol scale height is assumed to be $2 \mathrm{~km}$, which is a reasonable value for a typical boundary layer in our research region [36]. The polarized atmospheric path reflectance (i.e., $R p^{a t m}$ in Equation (3)) at the sensor level is accurately calculated using a doubling and adding method code, radiative transfer model RT3 [37], setting the surface reflectance to 0 (i.e., black surface). The LUT setting parameters are listed in Table 3 , including wavelength, aerosol model, AOD and illumination-viewing geometry.

Table 3. Parameter setting for LUT. AOD, aerosol optical depth.

\begin{tabular}{|c|c|c|}
\hline Dimensions & Values & Number of Values \\
\hline Wavelength (nm) & 670,865 and 1640 & 3 \\
\hline Aerosol model & $\begin{array}{l}\text { Desert dust, biomass burning, background/rural, } \\
\text { polluted continental, polluted marine and dirty pollution }\end{array}$ & 6 \\
\hline $\operatorname{AOD}(865 \mathrm{~nm})$ & $\begin{array}{l}\text { Interval }[0.02,0.5] \text {, increments of } 0.02 \text {, } \\
\text { interval }(0.5,1.0] \text {, increments of } 0.05 \text {, } \\
\text { interval }(1.0,1.5] \text {, increments of } 0.1\end{array}$ & 40 \\
\hline Surface reflectance & 0.0 & 1 \\
\hline Solar zenith angle & $0^{\circ}$ to $74^{\circ}$, increments of $1^{\circ}$ & 75 \\
\hline Relative azimuth angle & $0^{\circ}$ to $180^{\circ}$, increments of $3^{\circ}$ & 61 \\
\hline Viewing zenith angle $\left(^{\circ}\right)$ & $\begin{array}{c}3.4,7.81,12.24,16.68,21.12,25.56,30.01,34.45,38.89,43.34 \\
47.78,52.23,56.67,61.11,65.56,70.00,74.45,78.89,83.33 \text { and } 87.78\end{array}$ & 20 \\
\hline
\end{tabular}

\subsection{Retrieval Scheme}

A cost function $C F$ is defined as follows:

$$
\begin{gathered}
C F=\sqrt{\frac{1}{N w l} \cdot \frac{1}{N a n g} \sum_{m=1}^{N w l} \sum_{n=1}^{\text {Nang }}\left[\frac{R p^{\text {atm,meas }}-R p^{\text {atm,cal }}}{R p^{\text {atm,meas }}}\right]^{2}} \\
R p^{\text {atm,meas }}=R p^{\text {meas }}-T^{\downarrow} R p^{\text {surf }} T^{\uparrow}
\end{gathered}
$$

where Nwl and Nang are the numbers of wavelengths and viewing directions used in the AOD retrieval, and $m$ and $n$ denote the wavelengths and viewing directions, respectively. The superscripts meas and ${ }^{c a l}$ represent the measured and calculated polarized reflectance, respectively. Given a combination of aerosol model and AOD, $C F$ means the least squares fitting residual between the measurements of polarized atmospheric reflectance (i.e., the measured polarized reflectance $R p^{\text {meas }}$ corrected for the surface contribution via Equation (8)) and that calculated by LUT. The flowchart in Figure 2 shows the 
calculation of $C F$ for a given combination of the aerosol model and AOD. First, the 1640-nm polarized reflectance measurement is corrected for atmospheric effect using the following equation:

$$
R p^{\text {surf }}=\frac{R p_{1640}^{\text {meas }}-R p_{1640}^{\text {atm,cal }}}{T_{1640}^{\downarrow} \cdot T_{1640}^{\uparrow}}
$$

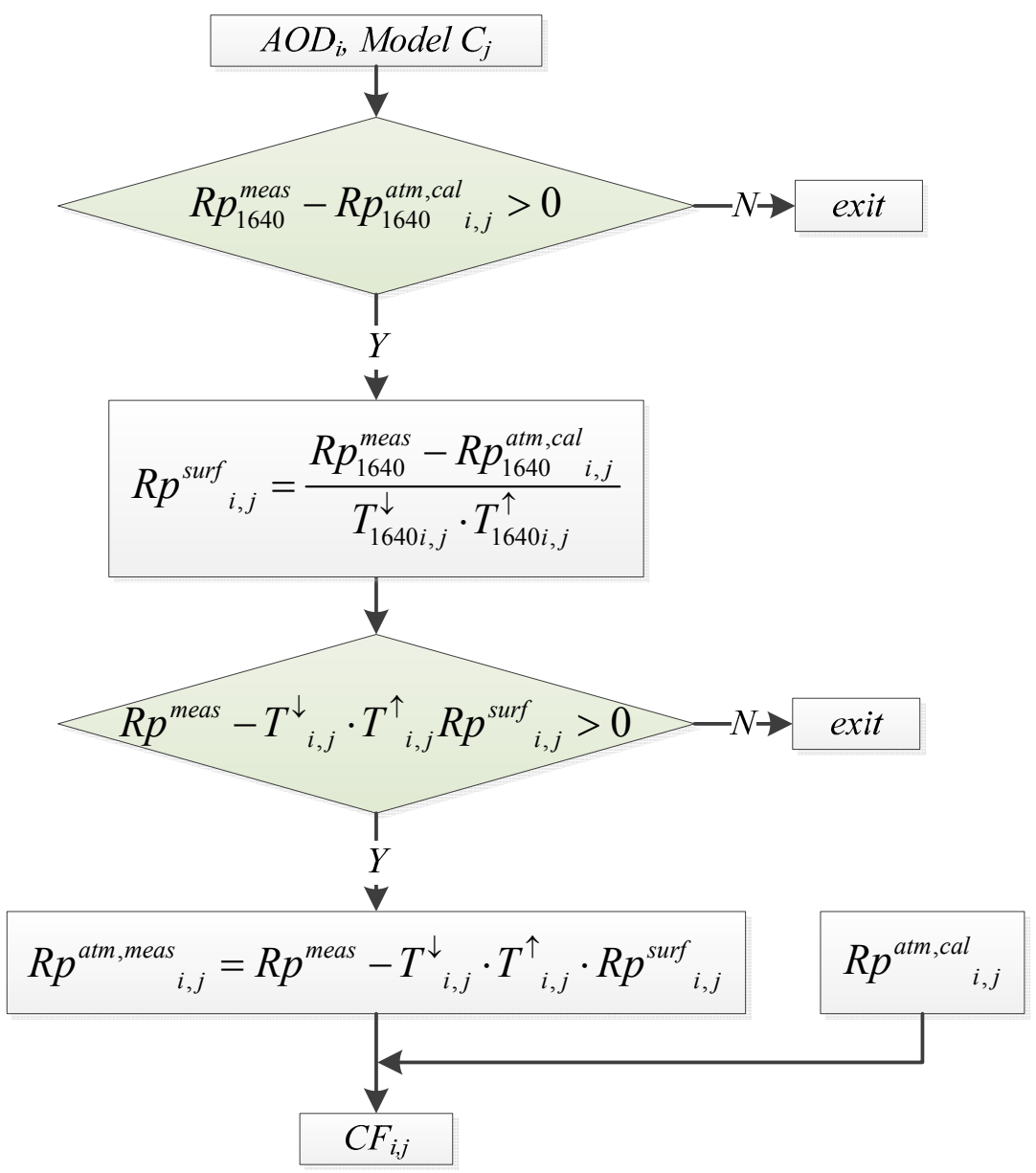

Figure 2. Flowchart for calculation of the cost function $C F$ ( $i$ and $j$ denote the aerosol models and AOD nodes in LUT, respectively).

The polarized surface reflectance is obtained. The measured polarized reflectances at visible and near-infrared bands are then corrected for surface contribution using the obtained $R p^{\text {surf }}$ (Equation (8)), and the measured atmospheric polarized reflectances are estimated. Lastly, the estimated $R p^{\text {atm,meas }}$ is compared to the simulated $R p^{a t m, c a l}$ in LUT via Equation (7), and $C F$ is calculated. Looping on all of the combinations of aerosol models and AODs in LUT, the AOD that minimizes the $C F$ value is accepted as the final retrieval result. The scheme attempts to simultaneously optimize the AOD retrieval and atmospheric correction of 1640-nm polarized surface reflectance (Figure 2). That is to say, by looping on all combinations of (AOD, model) couples, the best case to minimize the residual on the atmospheric items of the polarized reflectance $(670 \mathrm{~nm}$ and $865 \mathrm{~nm})$ is selected, and the surface reflectance subtraction is optimized by 1640 -nm measurements. 


\section{Results and Discussion}

\subsection{Polarized Surface Reflectance}

Figure 3 shows two examples of the polarized reflectance measured by AMPR at the 670-, 865- and 1640-nm bands, plotted as a function of viewing angles. These two examples were acquired during the first and second flights on 10 August 2012. Different viewing directions during one scan view different parts of the surface, and the observed polarized reflectance varies with both the angular-dependent radiation and the spatial variation of the surface properties. From these raw scans, we can perform preliminary identification of the surface variety. In Figure 3a, the polarized reflectance smoothly varies with viewing angle, whereas Figure $3 b$ displays several spikes with higher variability. This condition indicates that the surface type is relatively uniform for the scan (a), whereas different surface types are viewed in the scan (b). However, the polarized reflectance shows a similar decrease with the increase of scattering angles, and the fluctuations in the three bands are always highly correlated. The spectral dependence of the TOA polarized reflectance is similar to that of pure atmospheric scattering (i.e., it decreases as the wavelength increases), which is consistent with the hypothesis that the polarized surface reflectance is spectrally neutral in Section 3.1.
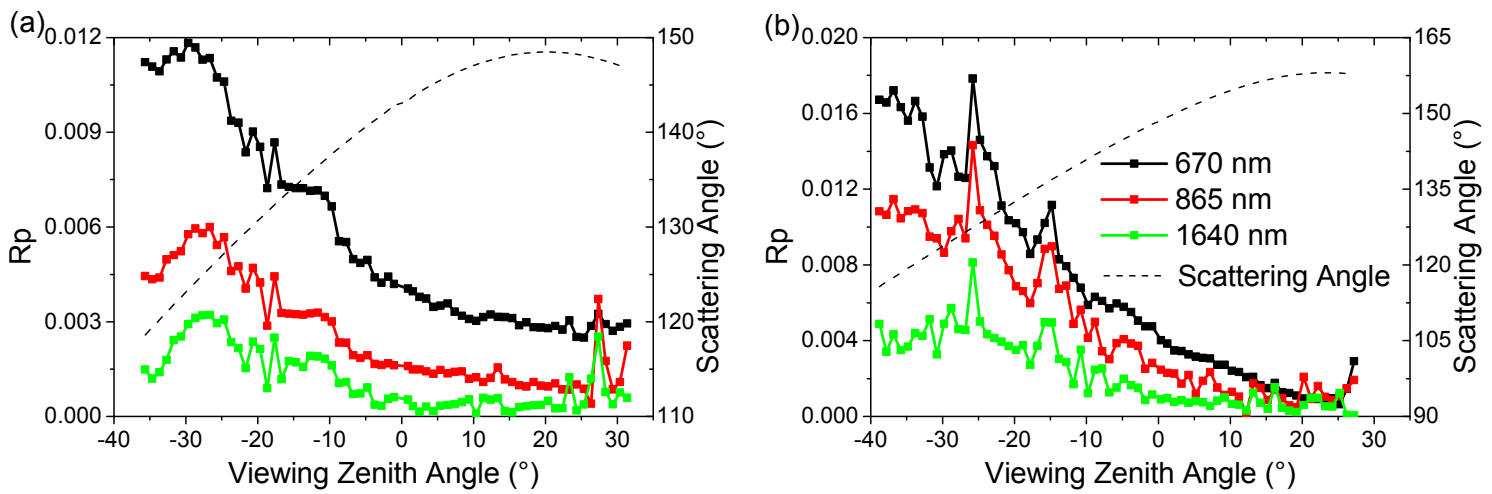

Figure 3. Examples of polarized reflectance measurements of AMPR at 670, 865 and $1640 \mathrm{~nm}$ plotted as a function of the viewing zenith angle. (a) Case of Flight 2; and (b) case of Flight 1.

To study the surface optical properties and to validate the applicability of the assumption that the surface polarization is spectrally neutral, a typical part of AMPR data (14:16:09 to 14:18:50 on 10 August 2012, a total of 165 scans with scattering angles ranging from $110^{\circ}$ to $150^{\circ}$ ) was selected, which was obtained in very clear sky conditions from observations of the second flight. All 165 measurements were corrected for molecular and aerosol scattering based on the aerosol optical thickness ( 0.05 at $865 \mathrm{~nm}$ on average) and the microphysical model derived from the simultaneous Sun-sky radiometer measurements at the Qichang site. The polarized surface reflectance at 670, 865 and $1640 \mathrm{~nm}$ were then obtained from calculations by RT3. Figure 4 shows scatter plots of polarized surface reflectance at $1640 \mathrm{~nm}$ against that at $670 \mathrm{~nm}$ and $865 \mathrm{~nm}$. The red solid lines indicate the linear regressions. The associated scattering angles in (a) and (b) are smaller than $145^{\circ}$, whereas the angles in (c) and (d) are larger than $145^{\circ}$. In Figure 4a,b, the polarized surface reflectances at $670 \mathrm{~nm}$ and $865 \mathrm{~nm}$ and that at $1640 \mathrm{~nm}$ are highly correlated, and both fitting lines are close to the 1:1 line. The slope values (1.03 and 0.985$)$ indicate that the average spectral variation of the polarized surface reflectance 
is not larger than $\pm 3 \%$, and the root-mean-square error (RMSE) is 0.0006 and 0.00046 , respectively. The deviations of the slopes from one can be attributed to the fixed input AOD and microphysical parameters for all samples during atmospheric correction. In Figures $4 \mathrm{c}$ and $4 \mathrm{~d}$, which are associated with larger scattering angles (greater than $145^{\circ}$ ), the spectral correlations of polarized surface reflectance at three bands are poor (i.e., the surface polarization is no longer spectrally invariant). A similar phenomenon was observed by Nadal and Bréon [38], Cairns et al. [32] and Elias et al. [13]. Therefore, the hypothesis on the spectral characteristic of surface reflected polarization in Section 3.1 is inapplicable to cases where the scattering angle is larger than $145^{\circ}$. A generally accepted interpretation is that a simple front-facet Fresnel reflection mechanism is not adequate for these larger scattering angles, and higher orders of scattering models might be necessary [39].
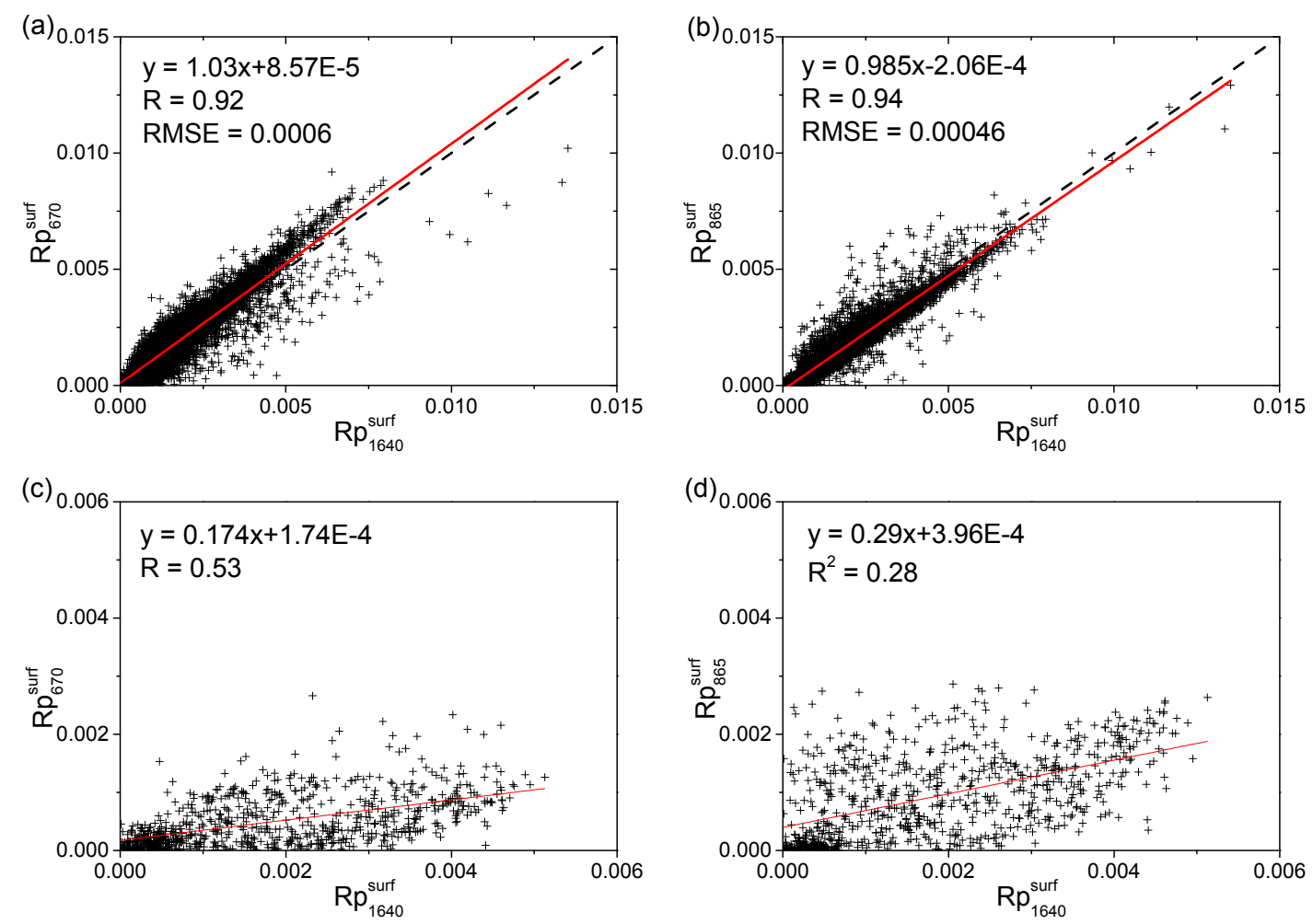

Figure 4. Scatter plots of polarized surface reflectance at 670 and $865 \mathrm{~nm}$ against $1640 \mathrm{~nm}$, respectively, based on 165 scans during Flight 2. (a,b) Scattering angle smaller than $145^{\circ} ;(\mathbf{c}, \mathbf{d})$ scattering angle larger than $145^{\circ} . R$ is the correlation coefficient, and RMSE represents root-mean-square error.

\subsection{Surface Contribution Correction Using 1640-nm Measurements}

In this section, we examine how well the polarized atmospheric reflectance at visible and near-infrared bands can be estimated using the 1640-nm measurement. Figure 5 shows the measured polarized atmospheric reflectance at $670 \mathrm{~nm}$ and $865 \mathrm{~nm}$ (lines with solid symbols), which are the AMPR measurements corrected for surface polarization based on the 1640-nm measurements. The simulated polarized atmospheric reflectance (lines with empty symbols), based on the Sun-sky radiometer measurements and radiative transfer model RT3, is also presented for comparison. The AOD is set to 0.04 and 0.14 for scans in (a) and (b), respectively, and the polluted marine aerosol model introduced in 
Section 3.2 is employed, considering that its Ángström coefficient is the nearest to the observation. Equation (9) is used to correct the atmospheric contribution of the 1640-nm measurements to obtain the polarized surface reflectance. After the surface reflectance is corrected using 1640-nm information, the measured polarized atmospheric reflectance at $670 \mathrm{~nm}$ and $870 \mathrm{~nm}$ agrees well with simulations, except for the near backscattering direction (Figure 5). The agreement in (a) is excellent, whereas the dispersion in (b) is relatively larger, although they matched on the whole. The reason may be the quick spatial variability in the sampled surfaces, which might have resulted in registration bias among four polarized measurement elements. Although the four polarization detectors of AMPR for one band were designed to simultaneously observe the same scene, a slight spatial mismatch may still exist among them (maximum 10\%), which would introduce false polarization errors in the estimated Stokes vector elements. The errors are insignificant for a uniform surface, but arise for a highly varied surface. Moreover, the scene mismatch is expected to be optimized for the satellite observation. Furthermore, its observing pixel is significantly larger (usually several kilometers in the case of polarimetry). Thus, the effects of surface spatial variability are averaged.

(a)

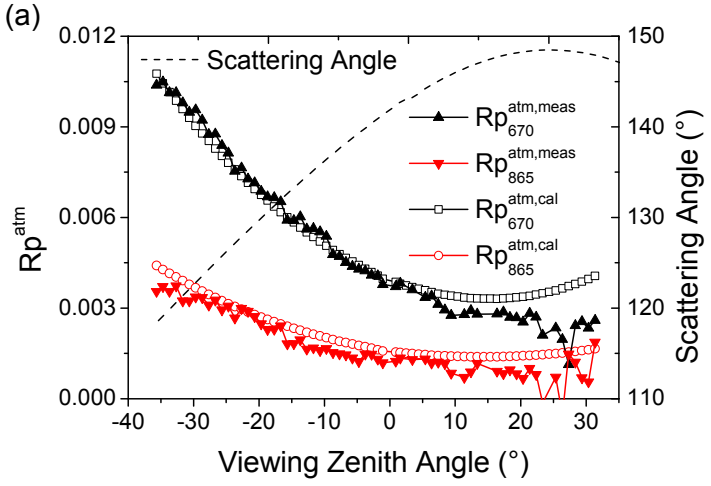

(b)

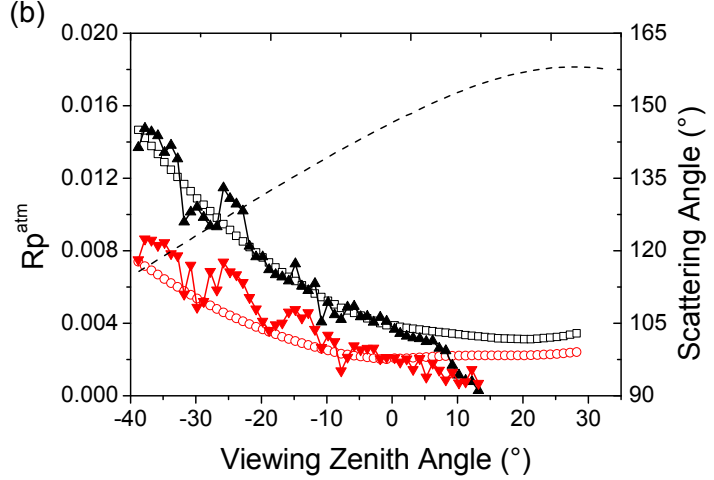

Figure 5. AMPR polarized reflectance measurements corrected for surface contribution based on measurements at $1640 \mathrm{~nm}$ and comparison with radiative transfer model RT3 calculations using Sun-sky radiometer AOD and polluted marine aerosol model as inputs. (a,b) These correspond to the two scans in Figure 3.

\subsection{AOD Retrieval Results and Validation}

According to the analysis in Section 4.1, AMPR measurements with scattering angles less than $145^{\circ}$ were used to retrieve AOD. First, the AOD retrieval scheme described in Section 3.3 was executed for every single angle observation in the scan course, for which the $N w l=2$ and $N a n g=1$. To reduce AOD noise caused by the surface spatial variability and instrumental false polarization errors, the retrieved AOD was averaged over a scan course (covering about $5 \mathrm{~km}$ cross-track or along-track, depending on the scanning mode) and then averaged over $10 \mathrm{~s}$ (about $10 \mathrm{scan}$ courses, covering about $0.5 \mathrm{~km}$ along-track). It is noteworthy that the average over so many pixels may be unnecessary for the satellite observations, for which the pixel size is approximately 10-times larger, and the false polarization errors would have been reduced to a certain extent. Figure 6 shows AOD at $865 \mathrm{~nm}$ retrieved from AMPR observations in the research areas of the three flights. The Sun-sky radiometer measurements are also presented for comparison. The AMPR retrievals agree well with Sun-sky radiometer measurements both for the 
clear condition (Figure 6a,c) and very clear condition (Figure 6b). The AMPR AOD, whose observed time is closest to that of site measurements, is chosen to calculate the errors by ignoring AOD spatial changes between the AMPR flight track and the ground-based site. The selected site measurements and AMPR retrievals of AOD are listed in Table 4. We estimated the uncertainties ranging from 0.01 to 0.06 and an average absolute error of approximately 0.03 in AOD for the improved algorithm with polarized surface reflectance estimated by 1640-nm measurements. For much higher AOD levels, which are common in the Beijing-Tianjin-Hebei region, the uncertainty in retrieved AOD may be higher.
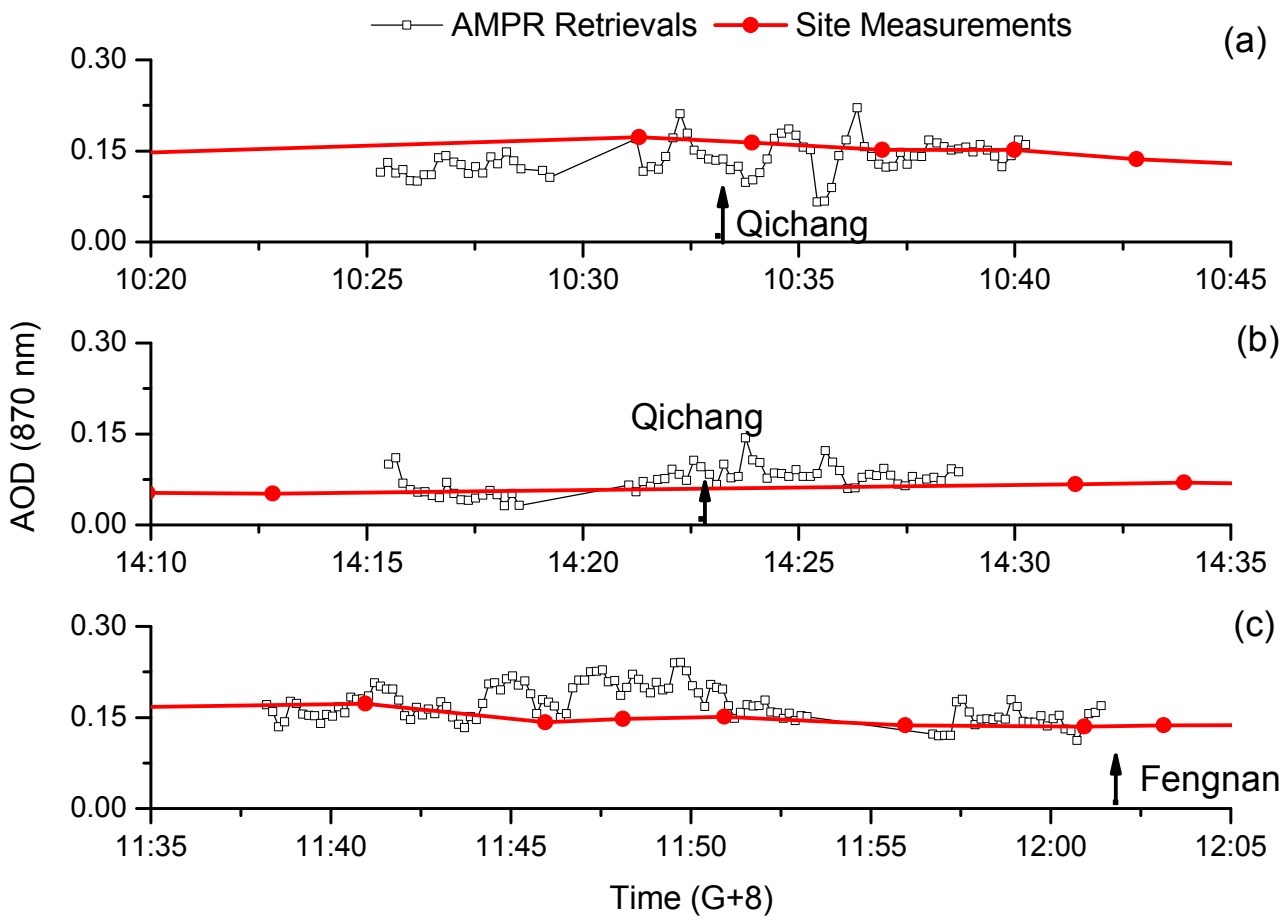

Figure 6. AMPR retrievals (AOD at $865 \mathrm{~nm}$ ) compared with Sun-sky radiometer measurements at Qichang and Fengnan sites. (a) Flight 1; (b) Flight 2; (c) Flight 3.

Table 4. List of ground-based measurements and AMPR retrievals of AOD for comparison.

\begin{tabular}{cccccc}
\hline Flight & Time $(\mathbf{G}+\mathbf{8})$ & CE318 & Time $(\mathbf{G}+\mathbf{8})$ & AMPR Retrievals & Differences \\
\hline \multirow{3}{*}{1} & $10: 31: 18$ & 0.173 & $10: 31: 14$ & 0.17 & -0.003 \\
& $10: 33: 55$ & 0.164 & $10: 33: 56$ & 0.102 & -0.062 \\
& $10: 36: 56$ & 0.152 & $10: 36: 51$ & 0.128 & -0.024 \\
& $10: 39: 59$ & 0.152 & $10: 39: 55$ & 0.142 & -0.01 \\
\hline \multirow{2}{*}{2} & $14: 12: 49$ & 0.052 & $14: 15: 30$ & 0.1 & 0.048 \\
& $14: 31: 24$ & 0.067 & $14: 28: 42$ & 0.087 & 0.02 \\
\hline \multirow{2}{*}{3} & $11: 40: 57$ & 0.173 & $11: 40: 53$ & 0.18 & 0.007 \\
& $11: 45: 57$ & 0.142 & $11: 45: 53$ & 0.179 & 0.037 \\
& $11: 48: 07$ & 0.148 & $11: 48: 03$ & 0.186 & 0.038 \\
& $11: 50: 56$ & 0.151 & $11: 50: 53$ & 0.196 & 0.045 \\
& $11: 55: 57$ & 0.137 & $11: 56: 43$ & 0.122 & -0.015 \\
& $12: 00: 56$ & 0.135 & 0.131 & -0.004 \\
\hline \multicolumn{5}{c}{ Maximum absolute error } \\
\end{tabular}




\section{Conclusions}

We present the AOD retrieval results based on AMPR multispectral angular polarization measurements, in which the 1640-nm observations were employed to estimate the polarized surface reflectance and the 670-nm and $865-\mathrm{nm}$ band measurements were used to derive AOD at $865 \mathrm{~nm}$.

The AMPR measurements of three flights over the Beijing-Tianjin-Hebei region in north China were utilized to demonstrate the capacity of $1640-\mathrm{nm}$ polarized measurements to evaluate surface polarization and the use in AOD retrievals. As suggested by these preliminary AMPR measurements, the spectral variability of polarized surface reflectance from $670 \mathrm{~nm}$ to $1640 \mathrm{~nm}$ is less than $3 \%$ on average when the scattering angle is less than about $145^{\circ}$. The measurement at $1640 \mathrm{~nm}$ is able to estimate the polarized surface reflectance at a shorter wavelength for every single viewing angle, and AOD can then be retrieved by single-angle measurement. By taking the average of AOD over multi-viewing directions and scan courses, the retrieval noise caused by instrument and polarization registration errors during the flight experiment was reduced. The noise was expected to be decreased in satellite observations. An average AOD error of approximately 0.03 (maximum of 0.06) at $865 \mathrm{~nm}$ is preliminarily obtained from three flights (AOD varies from 0.05 to 0.17 ) by comparing with the ground-based Sun-sky radiometer measurements.

Further observations and investigations over various surface types (e.g., soil and urban) and high polluted conditions (e.g., larger AOD) are expected to be performed in future studies to explore the robustness of the aerosol retrieval using additional polarized 1640-nm measurements.

\section{Acknowledgments}

This study was supported by the Key Project of Scientific and Technological Innovation of the Chinese Academy of Sciences under Grant No. KGFZD-125-13-006, the National Natural Science Foundation of China under Grant No. 41222007, Chinesisch-Deutsches Forschungsprojekt under Grant No. GZ659 and the Director Funds for Young Scholar of Institute of Remote Sensing and Digital Earth Chinese Academy of Sciences under Grant No. Y3SJ8400CX.

\section{Author Contributions}

Zhengqiang Li conceived of and designed this study and participated in drafting and revising the article. Lili Qie substantially contributed to the analysis and interpretation of data and drafted the article. Xiaobing Sun and Yanli Qiao designed the airborne observation. Bin Sun contributed to the acquisition and pre-processing of airborne data. Donghui Li designed the ground-based observation and analyzed the Sun-sky radiometer data. Zhao Liu and Wei Huang performed the ground-based observation. Han Wang, Xingfeng Chen and Weizhen Hou reviewed and edited the manuscript. All authors read and approved the manuscript.

\section{Conflicts of Interest}

The authors declare no conflict of interest. 


\section{References}

1. Boucher, O.; Randall, D.; Artaxo, P.; Bretherton, C.; Feingold, G.; Forster, P.; Kerminen, V.M.; Kondo, Y.; Liao, H.; Lohmann, U.; et al. Clouds and aerosols. In Climate Change 2013: The Physical Science Basis. Contribution of Working Group I to the Fifth Assessment Report of the Intergovernmental Panel on Climate Change; Stocker, T.F., Qin, D., Plattner, G.K., Tignor, M., Allen, S.K., Boschung, J., Nauels, A., Xia, Y., Bex, V., Midgley, P.M., Eds.; Cambridge University Press: Cambridge, UK, 2013.

2. Chowdhary, J.; Cairns, B.; Travis, L.D. Contribution of water leaving radiances to multiangle, multispectral polarimetric observations over the open oceans: Bio-optical model results for case I waters. Appl. Opt. 2006, 45, 5542-5567.

3. Stamnes, K.; Li, W.; Yan, B.; Eide, H.; Barnard, A.; Pegau, W.S.; Stamnes, J.J. Accurate and self-consistent ocean color algorithm: Simultaneous retrieval of aerosol optical properties and chlorophyll concentrations. Appl. Opt. 2003, 42, 939-951.

4. Kaufman, Y.J.; Tanré, D.; Remer, L.A.; Vermote, E.F.; Chu, A.; Holben, B.N. Operational remote sensing of tropospheric aerosol over land from EOS Moderate Resolution Imaging Spectroradiometer. J. Geophys. Res. 1997, 102, 17051-17067.

5. Kaufman, Y.J.; Wald, E.A.; Remer, L.A.; Gao, B.; Li, R.; Flynn, L. The MODIS $2.1 \mu \mathrm{m}$ channel-correlation with visible reflectance for use in remote sensing of aerosol. IEEE Trans. Geosci. Remote Sens. 1997, 35, 1286-1298.

6. Flowerdew, R.; Haigh, J. Retrieval of aerosol optical thickness over land using the ATSR-2 dual-look satellite radiometer. Geophys. Res. Lett. 1996, 23, 351-354.

7. Grey, W.M.F.; North, P.R.J.; Los, S.O.; Mitchell, R.M. Aerosol optical depth and land surface reflectance from Multiangle AATSR measurements: Global validation and intersensor comparisons. IEEE Trans. Geosci. Rem. Sens. 2006, 44, 2184-2197.

8. Diner, D.J.; Martonchik, J.V.; Kahn, R.A.; Pinty, B.G.N., Nelson, D.L.; Holben, B.N. Using angular and spectral shape similarity constraints to improve MISR aerosol and surface retrievals over land. Rem. Sens. Environ. 2005, 94, 155-171.

9. Torres, O.; Bhartia, P.K.; Herman, J.R.; Ahmad, Z.; Gleason, J. Derivation of aerosol properties from satellite measurements of backscattered ultraviolet radiation: Theoretical basis. J. Geophys. Res. 1998, 103, 17099-17110.

10. Torres, O.; Bhartia, P.K.; Herman, J.R.; Sinyuk, A.; Ginoux, P.; and Holben, B. A long-term record of aerosol optical depth from TOMS observations and comparison to AERONET measurements. J. Atmos. Sci. 2002, 59, 398-413.

11. Torres O.; Tanskanen, A.; Veihelmann, B.; Ahn, C.; Braak, R.; Bhartia, P.K.; Veefkind, P.; Levelt, P. Aerosols and surface UV products from Ozone Monitoring Instrument observations: An overview. J. Geophys. Res. 2007, 112, D24S47.

12. Hsu, N.C.; Tsay, S.C.; King, M.D.; Herman, J.R. Aerosol properties over bright-reflecting source regions. IEEE Trans. Geosci. Remote Sens. 2004, 42, 557-569.

13. Elias, T.; Cairns, B.; Chowdhary, J. Surface optical properties measured by the airborne research scanning polarimeter during the CLAMS Experiment. Proc. SPIE 2004, 5235, doi:10.1117/12.514245. 
14. Waquet, F.; Goloub, P.; Deuzé, J.L.; Léon, J.F.; Auriol, F.; Verwaerde, C.; Balois, J.Y.; François, P. Aerosol retrieval over land using a multiband polarimeter and comparison with path radiance method. J. Geophys. Res. 2007, 112, D11214.

15. Waquet, F.; Léon, J.F.; Cairns, B.; Goloub, P.; Deuzé, J.L.; Auriol, F. Analysis of the spectral and angular response of the vegetated surface polarization for the purpose of aerosol remote sensing over land. Appl. Opt. 2009, 48, 1228-1236.

16. Cairns, B.; Travis, L.D.; Russel, E.E. Polarization: Ground-based upward looking and aircraft/satellite-based downward looking measurements. Proc. SPIE 1997, 3220, 103-114.

17. Dubovik, O.; Herman, M.; Holdak, A.; Lapyonok, T.; Tanré, D.; Deuzé, J.L.; Ducos, F.; Sinyuk, A.; Lopatin, A. Statistically optimized inversion algorithm for enhanced retrieval of aerosol properties from spectral multi-angle polarimetric satellite observations. Atmos. Meas. Tech. 2011, 4, 975-1018.

18. Tanré, D.; Bréon, F.M.; Deuzé, J.L.; Dubovik, O.; Ducos, F.; François, P.; Goloub, P.; Herman, M.; Lifermann, A.; Waquet, F. Remote sensing of aerosols by using polarized, directional and spectral measurements within the A-Train: The PARASOL mission. Atmos. Meas. Tech. 2011, 4, 1383-1395.

19. Waquet, F.; Léon, J.F.; Goloub, P.; Pelon, J.; Tanré, D.; Deuzé, J.L. Maritime and dust aerosol retrieval from polarized and multispectral active and passive sensors. J. Geophys. Res. 2005, 110, D10S10.

20. Diner, D.J.; Xu, F.; Garay, M.J.; Martonchik, J.V.; Rheingans, B.E.; Geier, S.; Davis, A.; Hancock, B.R.; Jovanovic, V.M.; Bull, M.A.; Capraro, K.; et al. The Airborne Multiangle SpectroPolarimetric Imager (AirMSPI): A new tool for aerosol and cloud remote sensing. Atmos. Meas. Tech. 2013, 6, 2007-2025.

21. Cairns, B.; Travis, L.D.; Russel, E.E. The Research Scanning Polarimeter: Calibration and ground-based measurements. Proc. SPIE 1999, 3754, doi:10.1117/12.366329.

22. Mishchenko M.I.; Cairns, B.; Hansen, J.E.; Travis, L.D.; Kopp, G.; Schueler, C.F.; Fafaul, B.A.; Hooker, R.J.; Maring, H.B.; Itchkawich, T. Accurate monitoring of terrestrial aerosols and total Solar irradiance: Introducing the Glory mission. Bull. Am. Meteorol. Soc. 2007, 88, 677-691.

23. Deuzé, J.L.; Bréon, F.M.; Devaux, C.; Goloub, P.; Herman, M.; Lafrance, B.; Maignan, F.; Marchand, A.; Nadal, F.; Perry, G.; Tanré. Remote sensing of aerosols over land surfaces from POLDER-ADEOS-1 polarized measurements. J. Geophys. Res. 2001, 106, 4913-4926.

24. Cui, W.; Zhang, Y.; Yi, W.; Hong, J.; Qiao, Y. System design and implementation of multi-angle polarimeter. Acta Opt. Sin. 2012, 32, 0828003. (In Chinese)

25. Hansen, J.E.; Travis, L.D. Light scattering in planetary atmospheres. Space Sci. Rev. 1974, 16, 527-610.

26. Song, M.; Sun, B.; Sun, X.; Hong, J. Polarization calibration of airborne muti-angle polarimetric radiometer. Opt. Precision Eng. 2012, 20, 1153-1158.

27. Wang, H.; Sun, X.; Sun, B.; Liang, T.; Li, C.; Hong, J. Retrieval of aerosol optical properties over a vegetation surface using multi-angular, multi-spectral, and polarized data. Adv. Atmos. Sci. 2014, 31, 879-887.

28. Li, Z.; Li, D.; Li, K.; Xu, H.; Cheng, X.; Chen, C.; Xie, Y.; Li, L.; Li, L.; Lv, Y.; Qie, L.; Zhang, Y.; Gu, X. A Sun/sky-radiometer Observation Network with the extension of multi-wavelength polarization measurements. J. Remote Sens. 2015, 19, 495-519. 
29. Holben, N.B.; Eck, T.F.; Slutsker, I.; Tanré, D.; Buis, J.P.; Setzer, A.; Vermote, E.; Reagan, J.A.; Kaufman, Y.J.; Nakajima, T.; Lavenu, F.; et al. AERONET-A federated instrument network and data archive for aerosol characterisation. Remote Sens. Environ. 1998, 66, 1-16.

30. Bréon, F.M.; Tanré, D.; Leconte, P.; Herman, M. Polarized reflectance of bare soils and vegetation: Measurements and models. IEEE Trans. Geosci. Remote Sens. 1995, 33, 487-499.

31. Lafrance, B. Simplified Model of the Polarized Light Emerging from the Atmosphere. Correction of the Stratospheric Aerosol Impact on POLDER Measurements. Ph.D. Thesis, Université des Sciences et Techniques de Lille, Lille, France, 1997. (In French)

32. Cairns, B.; Travis, L.D.; Mishchenko, M.I.; Chowdhary, J. Aerosol retrievals over land surfaces: the advantages of polarization. In Proceedings of the AMS Annual Meeting, Albuquerque, NM, USA, 14-19 January 2001.

33. Maignan, F.; Bréon, F.M.; Fédèle, E.; Bouvier, M. Polarized reflectances of natural surfaces: Spaceborne measurements and analytical modeling. Remote Sens. Environ. 2009, 113, 2642-2650.

34. Diner, D.J.; Xu, F.; Martonchik, J.V.; Rheingans, B.E.; Geier, S.; Jovanovic, V.M.; Davis, A.; Chipman, R.A.; McClain, S.C. Exploration of a polarized surface bidirectional reflectance model using the Ground-Based Multiangle SpectroPolarimetric Imager. Atmosphere 2012, 3, 591-619.

35. Omar, A.H.; Won, J.G.; Winker, D.M.; Yoon, S.C.; Dubovik, O.; McCormick, M.P. Development of global aerosol models using cluster analysis of Aerosol Robotic Network (AERONET) Measurements. J. Geophys. Res. 2005, 110, D10S14.

36. Zhang, Q., Ma, X., Tie, X., Huang, M., Zhao, C. Vertical distributions of aerosols under different weather conditions: Analysis of in-situ aircraft measurements in Beijing, China. Atmos. Environ. 2009, 43, 5526-5535.

37. Evans, K.F.; Stephens, G.L. A new polarized atmospheric radiative transfer model. J. Quant. Spectrosc. Radiat. Transfer 1991, 46, 413-423.

38. Nadal, F.; Bréon, F.M. Parameterization of surface polarized reflectances derived from POLDER spaceborne measurements. IEEE Trans. Geosci. Remote Sens. 1999, 37, 1709-1719.

39. Wolff, M. Polarization of light reflected from rough planetary surface. Appl. Opt. 1975, 14, $1395-1405$.

(C) 2015 by the authors; licensee MDPI, Basel, Switzerland. This article is an open access article distributed under the terms and conditions of the Creative Commons Attribution license (http://creativecommons.org/licenses/by/4.0/). 